\section{LAS SOCIOLOGÍAS POST 68 Y LA CREATIVIDAD SOCIAL}

\author{
Celso Sánchez Capdequi \\ Universidad Pública de Navarra \\ ORCID iD: https://orcid.org/0000-0002-5255-2961 \\ celso.sanchez@unavarra.es
}

Cómo citar este artículo/Citation: Sánchez Capdequi, C. (2018). Las sociologías post 68 y la creatividad social. Arbor, 194 (787): a435. https://doi.org/10.3989/arbor.2018.787n1008

Recibido: 31 enero 2017. Aceptado: 13 noviembre 2017

RESUMEN: Este trabajo analiza la idea de creatividad social en relación con los acontecimientos de mayo del 68. Esta expresión aparece como foco de interés sociológico en un momento en el que las viejas estructuras de la modernidad burguesa se erosionan y emerge una nueva autoimagen del hombre postburgués: el artista. El texto explica los diferentes significados de la creatividad y los peligros que surgen en la sociedad moderna cuando la creatividad instituida oculta a la creatividad instituyente.

PALABRAS CLAVE: Creatividad; imaginario; artista; cambio social; modernidad burguesa e historia.

\section{SOCIOLOGIES POST 68 AND SOCIAL CREATIVITY}

Copyright: (C) 2018 CSIC. Este es un artículo de acceso abierto distribuido bajo los términos de la licencia de uso y distribución Creative Commons Reconocimiento 4.0 Internacional (CC BY 4.0).

ABSTRACT: This paper analyzes the idea of social creativity in relation to the events of May '68. This expression appears as a sociological focus of attention when old structures of bourgeois modernity are broken down and a new self image of postbourgeois man emerges: the artist. The text explains the different meanings of creativity and the dangers that appear in modern society when instituted creativity conceal instituent creativity.

KEYWORDS: Creativity; imaginary; artist; social change; burgueois modernity and history. 


\section{INTRODUCCIÓN}

Si alguna expresión de cambio social ha suscitado en la historia reciente la atención del amplio espectro de científicos sociales, y de la opinión pública en general, ha sido la de los acontecimientos de mayo del 68. Su irrupción coincide con el cuestionamiento y el desprestigio de símbolos, referentes y estructuras de una modernidad que ya no se reconoce en los viejos perfiles burgueses de la autoridad paterna en la familia, el especialista en la profesión, el súbdito en la política y el fiel en la religión. Las expectativas de nuevo cuño marcadas por un espíritu más reivindicativo y heterodoxo, afín al autodesarrollo personal y a la iniciativa individual, refractario a esquemas de autoridad y a paternalismos, valedor de una visión estética y esteticista de la biografía y de las relaciones sociales, y defensor de minorías y modos de vida alejados de las corrientes dominantes de la sociedad, componen un fondo coral que expresa la voluntad social de transformar el guion de los acontecimientos en el que los automatismos de la historia decimonónicos dejan su lugar a la agencia social.

En términos de análisis social y atendiendo a la publicación científica más reciente (Boltanski y ChiapeIlo, 2002; Florida, 2010; Koppetsch, 2006; Reckwitz, 2012), mayo del 68 es en especial expresión reveladora de un cambio de valores que madura en un curso histórico de muy largo recorrido. Además de transformaciones específicas en dominios sectoriales como los nuevos sujetos de la protesta representados por la juventud universitaria (Hobsbawm, 2000, p. 303), la transformación de las relaciones de producción hacia un cariz más espontáneo, informal y menos reglamentado (Boltanski y Chiapello, 2002), un modo de crítica social basada en la recuperación de las dimensiones lúdicas y expresivas de la condición humana (Marcuse, 1982), lo que se detecta en esa ola de cambios convulsos es una mutación honda y de calado en el magma soterrado de la imaginación humana en cuyas tramas se adivina una nueva autoimagen del hombre: la del artista creativo (Taylor, 2006, pp. 637 y ss.). Francia, y más en concreto París, se constituyen en símbolos que encarnan una mutación profunda y de una longitud de onda que va a expandirse con diferentes ritmos a lo largo y ancho del planeta.

Casi medio siglo después de aquellas jornadas intensas y reivindicativas su efecto sorpresa ha pasado. Queda su eco en las tramas secretas de los modelos sociales posteriores, por ejemplo en las del actual. Así como hasta fechas recientes, por la proximidad con su acontecer, se trataba de un evento que se enfocaba como principio de una serie de cambios con los que se iniciaba algo nuevo y desconocido, la reflexión actual sobre mayo del 68 y su ideal de creatividad se percibe, ya con más retrospectiva histórica, como un punto de llegada de un largo proceso histórico en el que empieza a estabilizarse un determinado estado de cosas: el imaginario de la creatividad y el arte como discurso nuclear del conjunto de la sociedad (Reckwitz, 2012).

\section{PRECEDENTES: EL DESPERTAR DEL DISCURSO DE LA CREATIVIDAD}

En el entorno de esos días señalados de finales de los 60 (y en sintonía con las revueltas del 68) un debate inédito se instala en los discursos académicos y sociales: la creatividad social. De manera súbita y espontánea el interés social y sociológico por esa cuestión crece y se consolida. El rechazo a las parálisis funcionales y a los privilegios de clase forjados en las viejas estructuras de la modernidad burguesa alienta la idea de autonomía social e individual deudora de un elemento fundamental habitualmente olvidado: la creatividad de la acción. En este contexto marcado por el protagonismo de las aulas universitarias y por una atmósfera de contestación canalizada como novedad por la juventud universitaria (Hobsbwam, 2000, p. 443), se produce lo que Charles Taylor denomina el giro expresivista de los años 60 (Taylor, 2006, p. 669), con el cual la sociedad del momento redescubre en el pálpito artístico-creativo del viejo romanticismo, y posteriormente, en el del arte de las vanguardias, un legado revolucionario promotor de una imagen de la sociedad muy distinta a la que empieza a dar síntomas de descomposición.

Se trata de algo que no era común hasta ese momento. La creatividad había ocupado un lugar menor o casi anecdótico en los grandes momentos del pensamiento sociológico. Autores tan sustantivos en la formación del imaginario sociológico como K. Marx, M. Weber, E. Durkheim y G. Simmel analizan periféricamente la creatividad, pero sin convertirse en el núcleo denso de sus investigaciones. Temáticas como el fetichismo de la mercancía en Marx, la experiencia carismática en Weber, la efervescencia ritual en Durkheim y la lucha entre las formas trascendentes y los procesos de formalización en Simmel, representan episodios sectoriales o de especial interés para otros objetivos explicativos de los citados autores. De igual modo, la teoría de la modernización que desde los años 30 del siglo pasado impera en el universo sociológico y que, entre otros, representa el sociólogo norteamericano Talcott Parsons, fija su atención en la adaptación 
y estabilización del sistema social. Su preocupación es la consolidación del orden social en unos entornos de enorme complejidad y turbulencias internacionales. Este enfoque teórico, hegemónico hasta los años 60 del siglo pasado, concibe la vida social a partir de un proceso de secularización que encarna el proceso inexorable de la diferenciación funcional de la sociedad y que desemboca en la convergencia de todo tipo de sociedad en el modelo de las democracias occidentales secularizadas, descentradas, diferenciadas e individualizadas.

Sin duda alguna, las contribuciones de los autores francfortianos de mitad del siglo pasado, como Walter Benjamin, Herbert Marcuse, Theodor Adorno, y posteriormente Jürgen Habermas, ofrecen una versión renovada de la sociedad moderna ya que coinciden en el diagnóstico de las cegueras del pensamiento identitario y en la necesidad de oxigenación críticodiscursiva con la que reorientar el curso errático de la razón moderna. Desde la otra parte del espectro político (conservador), Daniel Bell advierte del surgimiento de una subjetividad hedonista y esteticista que, en continuidad con una atmósfera moral permisiva y experimental, acaba erosionando los esquemas de rigor, autocontrol y disciplina inherentes a la racionalidad moderna. Ya en los 80 el arco de pensadores posmodernos como Francois Lyotard, David Harvey, Scott Lash y Frederic Jameson constatan, sin entrar en el corazón de la creatividad, el nacimiento de una sociedad en la que las esperanzas de emancipación universal de la modernidad declinan y los actores empiezan a priorizar las cuestiones del significante frente a las del significado, el fragmento frente a las visiones unificadas del mundo, la pulsión y expresión estética frente a las grandes síntesis de la teoría.

Sin embargo, a partir de los años 70 , surgen los primeros esbozos de una reflexión social y sociológica expresamente dedicada a la creatividad. Dicho de otro modo, esta empieza a ser pensada, meditada, convertida en problema. Tres serían los casos más representativos de este nuevo episodio de reflexión social: Cornelius Castoriadis (1988), Shmuel Eisenstadt (2000) y Hans Joas (1992). Estos autores van a entrar en los procesos de transformación de la sociedad moderna por la vía regia de la creatividad. Si bien es verdad que sitúan sus reflexiones en escenarios distintos, como el de lo ontológico en Castoriadis, lo histórico-evolutivo en Eisenstadt y lo intersubjetivo en Joas, se trata de contribuciones que comparten el hilo conductor de un elemento que, a pesar de su condición estructural en la vida humana, ha sido frecuente- mente apartado de la atención académica. En los tres autores se constata el impulso vivo del episodio social del 68 en la medida en que, a diferencia de los automatismos históricos prevalecientes en la teoría de la modernización, afrontan las dimensiones creativas del actor social en aspectos tan constitutivos de la experiencia social como la noción de orden, civilización e institución social. Los acontecimientos de la época llevan a estos marcos teóricos a explorar a fondo las condiciones de posibilidad de hechos sociales naturalizados por la sociología y a cuestionarse su supuesta consistencia ahistórica.

Castoriadis (1975/1989) centra toda su obra en la cuestión del imaginario. Griego de nacimiento y francés de adopción, perteneciente a la corriente trostkista del marxismo, además de psicoanalista y economista, este autor estudia las dimensiones inexpresadas de una ontología (judeocristiana) que, desde sus orígenes presocráticos, ha encontrado en la categoría de determinación (Bestimmheit) el fundamento de sus reflexiones. Desde Grecia a la modernidad burguesa la filosofía ha pensado el ser como una realidad autosuficiente y clausurada a lo que solo cabe llegar con el uso metódico de la razón. El ser es un orden preexistente, abstracto y formalizado que, ya se sitúe en el mundo de las ideas de Platón, en el marco histórico en el que se autorrevela el espíritu (Geist) en el caso de Hegel, o en las contradicciones históricas finalmente reconciliadas con la revolución exitosa en Marx, solo cabe ser constatado como una realidad cerrada y clausurada por la indagación filosófica. El soporte epistemológico que subyace a este enfoque filosófico incluye un yo cognoscente que se acerca a un objeto acabado y clausurado en su ser a través de la facultad racional, que proporciona un modelo de verdad como adequatio. De igual modo, todo lo que es y ocurre es lo que habrá de ser y ocurrir sin margen alguno para la novedad y, algo más, sin espacio para la intervención creativa de la acción humana.

Ante este dibujo filosófico Castoriadis (1988) profundiza en las tramas secretas de una realidad que, lejos de ser orden, es magma, y que constituye el principio dinámico y acausal de la complejidad del universo. Plantea una reflexión ontológica, de fundamentos, radical, por tanto, ya que explora la (in)consistencia de los supuestos irrebatibles de la filosofía occidental, como son el yo cognoscente, el mundo objetivo y la verdad como adecuación. Y lo hace convirtiendo en objeto de exploración el imaginario, la urdimbre viva, dinámica y transformadora desde la cual el ser se define como por-ser, como auto-alteración y, 
por tanto, como multiplicidad (p. 10). A su juicio, la estabilidad del mundo ha sido pensada en términos lógico-morales. Pero Castoriadis propone detener la mirada en lo sin-fondo del imaginario entendido como la condición de formalización de la conciencia lógica y formal. Se trata de las condiciones de posibilidad del pensamiento que no pueden ser pensadas. El imaginario actúa a partir de las tramas de sentido y al margen del principio de realidad ya que es su generador. En él no hay ser, sino caos generador de múltiples y provisionales formas de ser en ausencia de criterios lógicos y morales ahistóricos. Sus elementos originarios son imágenes y metáforas que, como bien sabía Nietzsche, se relacionan a partir de criterios de semejanza y similitud y cristalizan en realidades objetivas y objetivadas. Antes de pensar en una realidad acabada, el imaginario es creación de imágenes con las que se incorpora hemenéuticamente el sentido al mundo. La creación imaginaria es el nacimiento de un nuevo ideal de sociedad (Durkheim) en el que se proyecta el querer-ser intersubjetivo. Esto hace pensable el mundo. De esta forma, las sociedades podrán diferenciarse a partir de la relación que establezcan con su trasfondo imaginario: o bien ignoran su protagonismo creador y lo delegan en otras fuerzas externas como Dios, tradición o naturaleza, a las que Castoriadis denomina sociedades heterónomas, o bien asumen su responsabilidad creativa e incorporan elementos de autocorrección crítica y política, a las que define como sociedades autónomas.

En el caso de Shmuel Eisenstadt el plano de la experiencia desde el que enfoca la cuestión de la creatividad es el histórico-evolutivo. Este pensador judío y alumno aventajado de Edward Shils debate con la teoría de la modernización y sus esquemas de convergencia para explorar las posibilidades desconocidas que albergan las experiencias de la modernización. En los años 70 este autor, ya conocedor de la teoría del imaginario de Castoriadis, indaga en los múltiples modos de expresión que pueden ofrecer los procesos de modernización que han sido silenciados por la hegemonía universal del modelo propiamente judeo-cristiano. En su reflexión la novedad epistemológica radica en que sitúa a la modernización en sus encuadres civilizaciones y en conexión con sus cimientos simbólicos. Existen diferentes dinámicas históricas modernizadoras que promueven las diferentes civilizaciones en las que tienen lugar a partir de los presupuestos cosmovisionales sobre los que se asientan. La clave explicativa de esas dinámicas históricas vendría dada por el (diferente) grado de tensión que en todas ellas se establecen entre los planos de la trascendencia y la inmanencia. Eisenstadt (2000) detecta una creatividad cultural (pp. 19-20) inadvertida en la vida de las civilizaciones que desborda los límites presuntamente universales del modelo de civilización judeo-cristiano y que surge históricamente de la mano de la idea de trascendencia.

Pues bien, aquí juega un papel destacado el episodio histórico de la era axial de la que habla en primer lugar el filósofo alemán Karl Jaspers (1965). Con este concepto este autor remite al período histórico que abarca entre el 800 y 500 a. C. en el que surgen civilizaciones y religiones como la filosofía griega, el judaísmo, el cristianismo, el budismo, el confucianismo, el zoroastrismo y más tarde el islam. Todas ellas comparten una innovación cultural revolucionaria: la visión dualizada del mundo. La trascendencia y la inmanencia constituyen los dos planos de una experiencia que sustituye a la visión monista y compacta del mundo (Bellah, 2005, p. 71), inherente a las sociedades tribales y arcaicas (preaxiales). Si en estas el elemento nuclear es la conservación del orden cósmico al que liga su suerte y destino la vida humana, en las culturas axiales el elemento básico y novedoso es la idea de salvación individual. Se abre el período histórico en el que los actores toman conciencia del problema de la muerte y se hacen cargo de la orientación de su vida terrenal. Frente al plano trascendente de la salvación del alma, el plano de la inmanencia constituye el contexto en el que el actor individual crea y diseña modos de vida con los que ofrecer respuesta al interrogante ético del deber ser. Si aquel mundo es el de la beatitud y la vida eterna y, por ende, modelo ético del terrenal, en el más-acá rige la muerte y la contingencia. Todo es mutable, incierto e inestable: en definitiva, tiempo. Por ello, en este plano de la inmanencia los actores empiezan a asumir la conciencia de su libertad y su responsabilidad en la creación de formas de vida en las que la salvación es desafío prioritario. De algún modo esta moviliza la acción individual y la interacción político-social dentro de la esfera inmanente donde las biografías individuales y las instituciones políticas se rediseñan constantemente debido a su contingencia constitutiva.

El surgimiento de esta visión dual de las civilizaciones axiales constituye un paso irreversible en el proceso evolutivo de la especie. Su contribución esencial consiste en la aparición de lo que Merlin Donald (1991) denomina la cultura teórica que, personificada por los pensadores y portadores del conocimiento, como filósofos, profetas, místicos, ascetas, literatos, etc. otorgan a las ideas y al pen- 
samiento abstracto y universal un protagonismo inédito. Si bien en esas civilizaciones solo las minorías creativas (Toynbee, 1981, p. 343) pueden hacer uso competente de ese horizonte de conocimiento social debido a su elevado nivel de ilustración cultural, el embrión de su posterior y lenta democratización a lo largo de la historia ya está en curso de manera inexorable. De este modo, el problema de la salvación contribuye al surgimiento definitivo de una creatividad social en la memoria filogenética de la especie, en la que los primeros estadios cognitivos, es decir, el episódico, el mimético y el mítico se integran con el teórico (de la era axial) en la conciencia humana entendida como un "un sistema híbrido" (Donald, 1991, p. 364). La imaginación y la argumentación constituyen los cimientos simbólicos de los que se componen las respuestas éticas de los individuos ante el desafío de la trascendencia.

Y en este sentido, el avance evolutivo de la era axial ha acompañado desde entonces hasta la actualidad a la memoria cognitiva, cultural y moral de esas civilizaciones. En todas ellas reside el componente auto-corrector de la reflexividad y de la creatividad en lugar de mecánicas esenciales de origen divino, metafísico o natural. Y la singularidad de sus recorridos modernizadores descansa en las tramas cosmovisionales del conjunto de las civilizaciones. Más en concreto, en la específica manera de resolver la tensión entre trascendencia e inmanencia. De esta cuestión depende la mayor o menor tendencia al cambio de los marcos intramundanos. Así las cosas, las civilizaciones con una visión extramundana de la salvación, por ejemplo el budismo o el hinduismo, ofrecían pocos impulsos para una transformación política y social. Al mismo tiempo, las civilizaciones con una fuerte orientación intramundana, por ejemplo el judaísmo, el cristianismo y el islam, siempre en períodos concretos, mostraban una mayor tendencia a la transformación que a la conservación del mundo de modo que "el potencial para un proceso extenso y acelerado de transformación alcanzaba su valor máximo" (Joas y Knöbl, 2015, p. 318).

El sociólogo alemán Hans Joas representa el despertar de la creatividad en el plano de la reflexión sociológica. Afincado en los entornos del pensamiento pragmatista y reputada autoridad en la obra de G. H. Mead, Joas se convierte con su obra La creatividad de la acción (publicada originalmente en 1992) en uno de los primeros sociólogos que trata expresamente el problema de la creatividad. Y lo hace en un contexto poco favorecedor, como el de una corriente socio- lógica y cultural, el de la teoría de la modernización, que ensalza las reglas como herramienta explicativa del comportamiento social y del funcionamiento institucional. En este enfoque teórico la creatividad es lo por explicar, no lo que explica. Joas entiende que la sociología ha analizado la vida social sin acción o, con más precisión, sin entrar radicalmente en las consecuencias de la acción. Su potencial de contingencia y aleatoriedad ha sido reprimido por lógicas y mecánicas que alejan de la vivencia subjetiva y la convivencia intersubjetiva la aparición de lo inesperado y lo aleatorio; en concreto, la aparición de aquello que altera e interrumpe las líneas rectas y rutinarias de la vida social. Su concurso implica efectos y consecuencias que escapan a la capacidad de previsión y control del actor. En este sentido, Joas entiende que la creatividad es algo estructural en la acción. Se trata de la fuerza autotrascendente y renovadora de la interacción social que no se integra en las estructuras del orden, antes bien, las altera y, por lo mismo, las funda. Su relación directa con el cambio social y con la autonomía de la sociedad revela aspectos que han sido desatendidos en una sociología mayormente atenta a las continuidades de la vida social, y ajena a la capacidad de los actores para reorientar el curso de las cosas e intervenir voluntaria y consensuadamente en el mismo.

Joas no se plantea la acción como núcleo básico desde el que elaborar una nueva teoría social junto a la marxista, la funcionalista, la sistémica, etc. Más que proponer una teoría social creativa o de la creatividad piensa en el componente creativo subyacente a todo actuar humano. No hay manera de despojarse de su inquietante presencia porque lo mismo que altera funda. En ese sentido cualquier análisis sociológico habría de contar con los efectos inesperados y eventuales cambios derivados de la acción. Esto es algo que, según Joas, los sociólogos de los años 70 y 80 empiezan a realizar. A diferencia de las rígidas armaduras conceptuales de la sociología de la modernización, modelos sociológicos como la teoría del imaginario social de C. Castoriadis, el estructuralismo genético de P. Bourdieu, la teoría de la estructuración de A. Giddens, entre otros, vienen a hacer visible el momento de ruptura que inexorablemente ofrece la acción. Las denomina a todas ellas teorías de la constitución que, por un lado, dicen no a visiones deterministas y transhistóricas del curso temporal y, por otro, afirman la existencia del cambio social a partir de decisiones y acciones de los miembros de la sociedad (Joas, 1992, p. 336). 
La noción de creatividad de Joas se apoya en varios aspectos (Joas, 1992, pp. 218-285). Uno de ellos es la idea de un sujeto que no se acerca al mundo con el único cometido de conocerlo. Antes bien, el sujeto es parte del mundo que, antes que a conocer, le incita a actuar, a hacer, a intervenir en los desafíos que le interpelan. Su conexión con lo que en él acontece es directa, y la tarea del conocimiento solo es comprensible al albur de los estímulos del entorno, nunca en abstracto. Toda acción es respuesta al carácter situado del actor en un contexto específico. Otro aspecto sería la dimensión social de la acción. El actor forma parte de una atmósfera que le constituye medularmente. La figura del individuo no es el elemento inicial y esencial en el análisis de la creatividad ya que en ella se dan cita un sinfín de condicionantes sociales que la hacen posible. Joas se detiene en los códigos de comportamiento social como referencias inexcusables desde las que explicar las decisiones y acciones del yo. Y el último aspecto sería el de la relevancia del cuerpo en la acción social. No en vano, se trata de una instancia cuyo protagonismo ha sido menor por la hegemonía de la mente y la razón de cuño cartesiano. Joas recupera las dimensiones expresivas que intervienen en las propuestas sociales de los actores que se activan desde experiencias autotrascendentes conformadoras de valores y creencias, y posteriormente se articulan argumentativamente en el debate social.

En estas tres reflexiones que tratan expresamente la creatividad prevalece un rasgo común y compartido: la creatividad es una instancia potencial y posibilitante cuya presencia inesperada supone la aparición de lo desconocido en el plano ontológico, histórico-evolutivo e intersubjetivo. Se trata de lo que prepara (Bloch) un futuro estado de cosas que no puede anticiparse por la condición de alteridad del hecho creativo. Sin embargo, lo que ocurre en la actualidad es que la creatividad ha devenido imaginario social contemporáneo. Más que como potencia, hoy se ha actualizado como institución. Podemos hablar de la creatividad como escenario de normalización y como norma que define los contornos de lo pensable en nuestros usos sociales. En este sentido, mayo del 68 era el inicio de un modelo social en que se democratizó la figura del artista creador. Pero, como se expondrá a continuación, también fue final de un largo proceso histórico en el que culminaba la transformación radical de la sociedad moderna y de la autoconciencia humana.

\section{CULMINACIÓN DE UN LARGO PROCESO HISTÓRICO: LA CREATIVIDAD COMO NORMA}

En nuestro tiempo se ha producido un hecho inédito sin parangón en la historia humana. La creatividad se ha hecho realidad. Su alcance semántico impregna el conjunto de actividades y ámbitos de la vida social. Si hasta fechas recientes ha sido pensada como potencia instituyente, ahora se ha convertido en actualización instituida. La creatividad del arte y el artista se desplazan desde la periferia al centro de mando de la sociedad. La visión antagónica de la modernidad escindida entre el ámbito del cálculo y el de la creatividad se resquebraja. La creatividad artística ya no corresponde a un ámbito funcional de la sociedad. Se ha transformado en la palabra sagrada (Bröckling, 2013, p. 152) cuya fuerza semántica lo abarca todo.

Cuando se habla de creatividad como centro de la vida social, dos serían los rasgos que dan forma a tal experiencia.

En primer lugar, una búsqueda casi obsesiva de la novedad. El gran desafío del actor contemporáneo es el de la originalidad. Buena parte de las orientaciones del comportamiento social están movidas por la noción de ruptura con lo establecido. Se vive la necesidad imperiosa de aportar diferencia a todo lo que se hace. Las estructuras internas de las instituciones, los criterios de productividad de las organizaciones económicas, las pautas de estabilización de las empresas en el mundo globalizado y la autoimagen de los individuos, entre otros, son tramas sometidas a la novedad. Especial interés ofrece la creatividad dirigida a "la conformación del individuo mismo" (Reckwitz, 2012, p. 11) sobre la base de una propuesta de originalidad concebida como ruptura, diferencia y divergencia. Richard Rorty habla de "la cultura de la autocreación" (1991, pp. 159 ss.) para definir esta forma de estar en el mundo característico del hombre de nuestro tiempo.

Por otra parte, el modelo del artista, antes demonizado en los inicios de la modernidad burguesa, ahora cobra un protagonismo tan intenso que le convierte en un referente constante de actos y decisiones. En palabras de Ch. Taylor (2006), "existe un conjunto de ideas e intuiciones, aún no comprendidas del todo, que nos lleva a admirar al artista y al creador más que ninguna otra civilización; que nos convence de que una vida dedicada a la expresión o a la representación artística es eminentemente valiosa" (p. 45). La creatividad es representada por un perfil social que, por ejemplo, para hacer visible la peculiaridad de nuestro tiempo, no formaba parte del cuadro de los tipos de acción social que Max Weber (1987, pp. 20 y ss.) 
definió con carácter casi canónico para la reflexión sociológica (Knöbl, 2011, p. 289). El artista de las vanguardias de principios del siglo XX destaca en la aridez burocrático-funcional del modelo maquinista por el hecho de incorporar afectividad a sus obras. Esta carga afectiva se sitúa en el centro de la relación social transmitiendo y convocando al otro, al público. El modelo del artista, por tanto, representa un tipo de acción más integral que incluye sectores de la vida humana que habían sido menospreciados por la obsesión acumulativa de la modernidad burguesa.

Una vez analizado el significado de lo creativo como el foco vertebrador de la sociedad contemporánea se trataría de repensar la noción de modernidad que se proyecta desde este centro neurálgico estético. El elemento destacable sería que el énfasis funcional y racionalizador se debilita o se transforma sin que ese surco teleológico desaparezca, antes bien, se reubica. La dimensión estético-creativa no viene a desdecir las poderosas tendencias calculativas y normativas que han predominado en la modernidad inicial. Si acaso, su presencia sustantiva en los actuales modos de vida llena un déficit estructural que acompaña los dos últimos siglos de la historia humana: la ausencia de la afectividad como elemento inexcusable de la vida social. La expansión de la creatividad constituye un síntoma, un indicio de algo que exigía presencia en los actos sociales pero que había sido maniatado por la racionalidad funcional para una mejor gestión técnica de la complejidad de las sociedades avanzadas. Los actores quieren expresarse más allá del perímetro de lo doméstico y lo funcional, pretenden mostrar sus afectos o incorporarlos a buena parte de sus contextos de acción, aborrecen un modelo de vida que parte en dos polos totalmente incomunicados, razón y afecto, la dimensión integral de la condición humana. Un paso decisivo tiene lugar cuando los perfiles característicos de la creatividad contemporánea como gastrónomos, diseñadores, publicistas, modistas, ingenieros, etc., liberan su afectividad en el manejo objetivo de los artefactos técnicos de sus oficios y conjugan libre y experimentalmente la convivencia de sendos dominios de la vida humana y profesional, hasta tiempos recientes enfrentados e incomunicados.

La modernidad estética promueve la creatividad como instancia de reencuentro de una forma de vida descompensada, durante gran parte su recorrido, hacia la esfera técnico-productiva. Desde los años 70 (más en concreto, desde el umbral histórico de mayo del 68) se constata una transformación paulatina pero insistente que echa raíces en una vertiente de la tra- dición igualmente moderna, como es la romántica, pero soslayada o alejada de los centros de organización y decisión social, y que consuma su irrupción y consolidación estructural desde el momento en que "las ideas y prácticas de las viejas contraculturas y subculturas se transforman en hegemónicas" (Reckwitz, 2015, p. 14). Dicho de otro modo, el ideal de la creatividad se convierte en el segmento dominante de la cultura del presente en sus formas de trabajo, consumo y relación.

En este orden de cosas, podría hablarse de una visión de la modernidad que ya no responde al origen ascético-burgués glosado, en especial, por Max Weber, en la medida en que la racionalidad medios-fines y la experiencia estética por separado son básicamente "puntos extremos de un continuum" (Reckwitz, 2012, p. 28). Es decir, no son inexorablemente excluyentes entre sí. Más bien, se han escindido debido a un modo de vida que promovió la tendencia compulsiva hacia la eficacia, y en el que el medio técnico se convirtió en finalidad social. Sin embargo, a día de hoy lo que predomina en nuestras miradas de la experiencia ordinaria son combinaciones cruzadas en las que la estética adereza y nutre las actividades sociales de todo tipo y la razón instrumental se resitúa en el plano de los medios técnicos. Estamos, por tanto, ante un cambio de la estructura social. El arte se ha desplazado hacia el centro de las estructuras organizadoras del modo de vida contemporáneo. El artista y sus rasgos tales como la experimentación, la originalidad, la sed de reconocimiento, la lucha contra lo canónico, entre otros, se imponen en todos los órdenes de lo social. La modernidad no es algo monolítico. Dicho de otro modo, "la modernidad no es sólo una maquinaria de des-estetización, también de estetización" (Reckwitz, 2012, p. 34). En este sentido, la consolidación de la creatividad como valor prevaleciente supone el nacimiento de un modelo de subjetividad que se expande por los diversos recintos de la sociedad y que no encaja con las pautas identitarias de origen burgués. El alma romántica y el alma ilustrada ya no caminan por separado. El sujeto creador actual las cruza en sus producciones. Por ello, no se identifica con el artista romántico abandonado a su sola meditación sin contacto con el mundo y sus recursos profanos, ni con el técnico o especialista que sigue pautas mecánicas del trabajo en cadena sin contacto con sus tramas emocionales.

En este contexto surge una nueva versión del modo de vida metódico, cuyo objetivo ya no es la disciplina y el autocontrol afectivo sino la autoafirmación y la experimentación. Surge una nueva moral del trabajo basa- 
da, por un lado, en la importancia de los contenidos del trabajo y, por otro, en las expectativas de la satisfacción subjetiva y la autorrealización individual (Koppetsch, 2006 , p. 9). Esta sistematización de la conducta, que viene dada también por la difusión global del soporte tecnológico, descansa sobre un elemento de no-planificación y aleatoriedad del trance creativo que se armoniza con la racionalidad instrumental. De algún modo, "la innovación técnico-económica y la creatividad estética se asocian" (Heubel, 2002, p. 19). Aquí la racionalidad técnica se acopla a la exigencia de racionalidad estética consistente en la producción orientada a la novedad. Aunque entre ambas formas racionalidad no existe ninguna homología estructural, toda vez que la racionalidad formal tiende a procesos anónimos guiados por una lógica de incremento de los rendimientos frente a la dimensión opuesta de la racionalidad estética orientada a la producción de la novedad ante un público al que hay que encantar desde el deleite emocional, el imaginario de la creatividad resulta de una complementariedad entre ambos modos de la racionalidad.

\section{GENEALOGÍA DEL IMAGINARIO DE LA CREATIVIDAD}

Las reflexiones sociológicas más recientes sobre la creatividad, emparentadas con las expuestas anteriormente, introducen una mirada bien distinta. Se enfrentan a una creatividad instituida como forma de vida (Lebensform). Su condición de hecho social cristalizado no sugiere análisis de la creatividad referidos a lo que está por-venir, más bien a lo que ya está consumado. Sobre este particular Andreas Reckwitz (2012) realiza un estudio genealógico que describe la dinámica histórica que desemboca en el modelo social actual y que revela la fuerza incontinente del arte para colonizar otras esferas de la modernidad. Ese proceso atravesó por diferentes fases: en primer lugar, fue $n i-$ cho; tiempo después, se transformó en contracultura; y, por último, se convirtió en norma.

En los primeros momentos de la modernidad el arte ocupa un espacio y un protagonismo marginal y subsidiario. Es el nicho en el que se condensan los perfiles y las actividades socialmente desvirtuadas y las incipientes voces discordantes con el sistema de producción capitalista. El núcleo de la sociedad lo constituye la conciencia burguesa, la filosofía maquinista, la secularización de creencias e ideales, el control técnico del mundo, la neutralización afectiva del cuerpo humano y la hegemonía del individuo autorreferencial y autosuficiente. Asimismo, el sustento normativo de la religión contribuye a la catalogación y convalidación moral de los comportamientos sociales en los que la bohemia se concibe como la periferia marginal de los núcleos de decisión política. El arte se ocupa de la belleza y el artista la engendra sin más relación con los centros de decisión de la sociedad que la de ser un mero episodio de compensación afectiva en medio de la erosión emocional provocada por la conciencia instrumental burguesa. Proporcionan disfrute, huida de la realidad y ensoñación onírica. Pero no influyen sobre la realidad entendida como una experiencia radicada en los procesos de actividad económica. En este esquema la socialidad artística se localiza en la bohemia donde se liberan los rigores morales de la sociedad y donde una atmósfera de permisividad y laxitud impregna las biografías y las experiencias de los artistas. Se trata de contextos que facilitan determinadas actividades desempeñadas por personalidades excéntricas y excepcionales por su contacto con la inspiración ultramundana. El perfil del artista queda recogido en la figura del genio. Su obra está motivada por factores ajenos y extraños a la conciencia burguesa rígida y disciplinada. Su estilo de vida se encarna en una minoría aristocrática no integrada socialmente porque su actividad profesional no encaja en la tipología de los oficios reconocidos orientados básicamente hacia el trabajo remunerado. La gran aportación social es la educación sentimental con la que refina la rudeza y la insensibilidad burguesa.

Sin embargo, ya en este período de la experiencia artística se anuncian voces minoritarias que cuestionan los usos y abusos de la insaciable economía capitalista. En 1851 tiene lugar en el Cristal Palace de Londres la I Exposición Universal en la que los destellos de la opulencia en sectores como la arquitectura, los objetos técnicos, la producción industrial, el interiorismo, absorben la atención de esas masas anónimas sedientas del calambrazo de la nueva divinidad secular: el consumo. Una de las primeras expresiones de rechazo es el movimiento denominado Art-and-Craft, que se dirige contra la producción industrial estandarizada y promueve una interpretación alternativa del trabajo y el consumo. Este movimiento pretende anular la diferencia insalvable entre trabajo y arte acudiendo a un concepto integrador como el de artesanía. Con él se trata de hacer una defensa de los artefactos artesanales producidos por el hombre y para el hombre, donde no hay primacía de la producción ni de la circulación, donde el productor y el usuario no se someten al predominio del objeto y donde el trabajo y sus obras invitan a la realización y al disfrute personal respectivamente. Consistiría, por tanto, en un intento de cuestionar el cariz impersonal y objetivo de la economía capitalista al ver en la actividad artesanal los modos de trabajo 
que salvaguardan la expresividad de los individuos en la producción y el uso de las mercancías.

Esta voz minoritaria e inaudible de rechazo a las lógicas de la economía capitalista nunca ha dejado de estar presente en la vida moderna. Es más, se fortalece en los años 50 y 60 del siglo XX. Esta transformación tiene lugar, primera y tímidamente, en los procesos de producción y de consumo con la llegada del sistema fordista. Radicado originariamente en Estados Unidos y basado en el imaginario de la affluent society, el fordismo se consolida a partir de una contradicción de base. Por un lado, insiste en el proceso de racionalización de la modernidad burguesa orientado hacia una sociedad hiperorganizada, centrada en la planificación económica y diseñada bajo el modelo de la gran corporación con una rígida jerarquía y división del trabajo. Asimismo, activa una profunda estetización de la vida cotidiana. Las clases medias encarnan los primeros episodios de actores contemporáneos que encuentran sentido en el consumo masivo en el que ya no predomina el valor de uso sino el valor estético y simbólico de las cosas. Todo esto es posible por la revolución técnica que se está produciendo en ese momento histórico y que permite la difusión y el disfrute a gran escala de la estimulación estética. La radio, el cine, el tocadiscos y, más tarde, la televisión, se brindan a la novedosa recepción estética.

A mitad de siglo pasado surgen las primeras expresiones de rechazo del sistema fordista. Una mutación axiológica, de la que habla Charles Taylor en referencia a ese giro expresivista que tiene lugar en la sociedad de los años 60 del siglo pasado (primero en Estados Unidos), se produce con el resultado de una alteración del cuadro global de la sociedad. Ese giro tiene en la experiencia artística su núcleo fundamental. Ya no se trata tanto de un consumo masificado y organizado de la producción, sino de una reivindicación de la figura del artista como modelo de vida. Y en concreto, del artista de las vanguardias. Todos los individuos están llamados a orientar su vida desde sus parámetros basados en la expresividad. Esta concepción del arte se sitúa en las antípodas de la estética de la cultura de masas y del conformismo social del sistema fordista. Reivindica el arte como algo que excede el espacio de la belleza de la modernidad burguesa y que cobra vida como núcleo directriz de las prácticas sociales. Ya no se trata de una parte de la experiencia humana, sino de la experiencia humana integralmente concebida desde la expresividad estética. Términos como autenticidad, autodesarrollo, plenitud, vivencia etc. se convierten en referentes semánticos del discurso social y, al mismo tiempo, del discurso académico de la psicología y la pedagogía, como ocurre en los casos de A. Maslow, E. Fromm y H. Marcuse, entre otros.

De algún modo, las tramas del romanticismo y las vanguardistas confluyen, renovando el sustrato de creencias de la sociedad. La vida planificada del futuro y la experiencia volcada hacia el recuerdo del pasado se debilitan ante una existencia centrada en el vértigo del presente. Así las cosas, este episodio post-romántico y post-vanguardista se caracteriza por la democratización de la creatividad espontánea, que "exige experimentar la vitalidad del momento, vindicar la espontaneidad contra la rutinización, contra la repetición de actos idénticos en la creación de lo nuevo" (Reckwitz, 2010, p. 465). La creatividad entendida como la capacidad de elaborar ideas y actos imprevistos y novedosos, de combinar de manera inédita distintas representaciones y prácticas o de trascender fronteras y límites rígidamente arraigados, se presenta como presupuesto natural de un sujeto que se realiza a sí mismo.

Esta mutación simbólica de la sociedad se corresponde con numerosos movimientos de protesta que ganan visibilidad social e influencia sobre la opinión pública. A partir de este momento, la dimensión estética se transforma en contracultura a través de la que se proyectan, de manera múltiple y diversa, visiones alternativas a la imperante. La visión burguesa del mundo queda seriamente cuestionada. Elementos de la vida creativa, que hasta ese momento existía en nichos sociales diseminados, se erigen, se radicalizan y se configuran como referentes atractivos favorecedores del cambio de valores. Recogen una sensibilidad diversa y comprometida dirigida hacia temas como la defensa medioambiental, los derechos de la raza negra y de la mujer, la oposición ante la guerra, los excesos de la explotación capitalista, etc.

En este orden de cosas, en los años 80 la creatividad artística se convierte en norma. El arte se sitúa en los centros de decisión y organización de la sociedad. La bohemia artística abandona la periferia para, luego de representar la posición antagónica y alternativa a la sublimación burguesa y fordista de la producción, convertirse en voz cantante del presente histórico. El referente simbólico de la innovación habla en favor del gesto creativo como el impulso irrenunciable del bienestar social. Arte y técnica se cruzan y se solapan. Y lo hacen liberando la inventiva en el trance experimental de la creatividad, en el que los instrumentos técnicos ofrecen sus recursos a la ensoñación y a la imaginación. Este binomio ya no corresponde en exclusiva a un segmento o clase social, ni a un perfil pro- 
fesional, ni a un entorno cultural. La complejidad tecnológica ya no es, per se, un obstáculo o impedimento que bloquea la proyección creativa. Muy al contrario, convive con la invención y es parte sustantiva de las realizaciones individuales en los diferentes planos de la experiencia social. Las nítidas fronteras de antaño entre sendos espacios sociales se diluyen.

Este hecho social de reciente factura describe las claves simbólicas del tiempo actual. La experiencia artística invade los diferentes planos de la cultura contemporánea. Comparece como una oportunidad para la autoexpresión individual en el curso de la acción, pero también como un desafío irremplazable que obliga a generar originalidad. Su normalización se traduce en exigencia, cuando no en coacción. Solo los espíritus más originales tienen garantizada la presencia en los espacios densos y decisivos de la sociedad. Reckwitz (2015) habla de la paradoja inherente a la normalización estética. No en vano, su carácter de desafío irremplazable se vive, en determinadas ocasiones, como una disciplinización de "segundo orden" (Reckwitz, 2015, p. 46), desde el momento en que no se condensa en los cuerpos domesticados, sino en la imperiosa necesidad de "marcar distancia frente a lo actual y las rutinas e incluir un elemento de lo sorprendente y lo imprevisible" (Reckwitz, 2015, p. 46). La creatividad ha devenido nuevo destino inexorable que convierte a todo individuo en artista pero con desiguales resultados en términos de originalidad.

\section{CONCLUSIÓN: LAS ENCRUCIJADAS DE LA CREATIVIDAD}

Se decía anteriormente que la época actual tiene algo de inédito en la historia. La creatividad se ha convertido en norma y en normal. Las voces de la academia que clamaban por una sociedad diseñada desde los parámetros de la creatividad artística pueden verse representadas en el actual modelo de la sociedad moderna que se consolida con motivo de los acontecimientos de mayo del 68. Es difícil saber si aquellas esperanzas en futuros modelos sociales animados por la utopía estética hoy se considerarían culminados y consumados en el actual. La creatividad se ha hecho realidad, más en concreto, principio de realidad. $\mathrm{Y}$ en ese sentido, la creatividad ya no solo libera, expande y estimula el ingenio y la libertad, también ofrece frenos, resistencias y coacciones. La normalización de la creatividad obliga al conjunto de los actores a ofrecer originalidad en cada aspecto de su vida, a vivir la creación como un imperativo. No es que queramos ser creativos, es que debemos serlo (Reckwitz, 2012, p. 10). La propia sociedad premia esa creatividad bajo etiquetas de enorme prestigio en nuestros días, como innovación, emprendimiento, talento, etc. Y por diferentes motivos de orden educativo, económico, cultural etc. no todos los individuos están en iguales de condiciones de acceder a las máximas cotas de reconocimiento social. Una nueva escisión social se trama en el seno de la cultura de la creatividad.

Pero de igual o mayor importancia es el problema del significado de la creatividad en nuestros usos sociales. Hoy es principio de realidad y, en ese sentido, su condición de hecho social consolidado en las conciencias de los actores puede hacer olvidar que ha sido propiamente imaginada y proyectada. Es decir, que ha sido creada. El peligro de nuestro tiempo es que esta sociedad vea creatividad por doquier salvo en los procesos instituyentes que la crearon. Negar esta realidad implica que el concepto de creatividad instituida se explique $\sin$ creatividad instituyente, sin esas dimensiones potenciales (Castoriadis, Eisenstadt y Joas) que forman parte de la génesis del hecho social y que lo convierten en algo contingente y provisional. Mayo del 68 fue una fecha histórica cargada de resonancias. Con ella nacía la sociedad de la democratización de la creación. Y también nuevas expresiones de desigualdad social.

\section{BIBLIOGRAFÍA}

Bellah, R. N. (2005). What is Axial about the Axial Age? Archives Européennes de Sociologie, XLVI (1), pp. 69-87. https://doi. org/10.1017/S0003975605000032

Boltanski, L. y Chiapello, É. (2002). El nuevo espíritu del capitalismo. Madrid: Akal.

Bröckling, U. (2013). Das unternehmische Selbst. Francfort del Meno: Suhrkamp.

Castoriadis, C. (1988). Los dominios del hombre: las encrucijadas del laberinto. Barcelona: Gedisa.
Castoriadis, C. (1975/1989). La institución imaginaria de la sociedad. Barcelona: Tusquets.

Donald, M. (1991). Origins of Modern Mind. Three Stages in the Evolution of Culture and Cognition. Cambridge (Mass.): Harvard University Press.

Eisenstadt, S. N. (2000). The Civilizationa Dimension of Sociological Analysis. Thesis Eleven, 62, pp. 1-21. https://doi. org/10.1177/0725513600062000002
Florida, R. (2010). La clase creativa. La transformación de la cultura del trabajo y del ocio en el siglo XXI. Barcelona: Paidós.

Heubel, F. (2002). Das Dispositiv der Kreativität. Darmstadt: Wissenschaftliche Buchgesellschaft.

Hobsbawm, E. (2000). Historia del siglo XX. Barcelona: Crítica.

Jaspers, K. (1965). Origen y meta de la historia. Madrid: Revista de Occidente. 
Joas, H. (1992). Die Kreativität des HandeIns. Francfort del Meno: Suhrkamp.

Joas, H. y Knöbl, W. (2015). Teoría social. Madrid: Akal.

Knöbl, W. (2011). Makrotheorie zwischen Pragmatismus und Historismus. En: Hollstein, B., Jung, M. y Knöbl, W. (eds.). Handlung und Erfahrung. Francfort del Meno / New York: Campus Verlag, pp. 273-315.

Koppetsch, C. (2006). Das Ethos der Kreativen. Constanza: UVK Verlagsgesellschaft.
Marcuse, H. (1982). Eros y civilización. Barcelona: Seix Barral.

Reckwitz, A. (2010). Das hybride Subjekt. Weilerwist: Velbrück Wissenschaft.

Reckwitz, A. (2012). Die Erfindung der Kreativität. Francfort del Meno: Suhrkamp.

Reckwitz, A. (2015). Ästhetik und Gesellschaft. Ein analytischer Bezugnahmen. En: Reckwitz, A., Prinz, S y Schäfer, H. (eds.). Ästhetik und Gesellschaft. Francfort del Meno: Suhrkamp, pp. 9-52.
Rorty, R. (1991). Contingencia, ironía y solidaridad. Barcelona: Paidós.

Taylor, Ch. (2006). Las fuentes del yo. Barcelona. Paidós.

Toynbee, A. J. (1981). Estudio de la historia (vol. 1). Madrid: Alianza.

Weber, M. (1987). Economía y sociedad. México: Fondo de Cultura Económica. 